AEC Research and Development Report

\title{
RESIDUAL STRESSES IN THORIUM SLUGS
}

by

J. W. Joseph, Jr. and J. W. Walker

Pile Engineering Division

September 1956

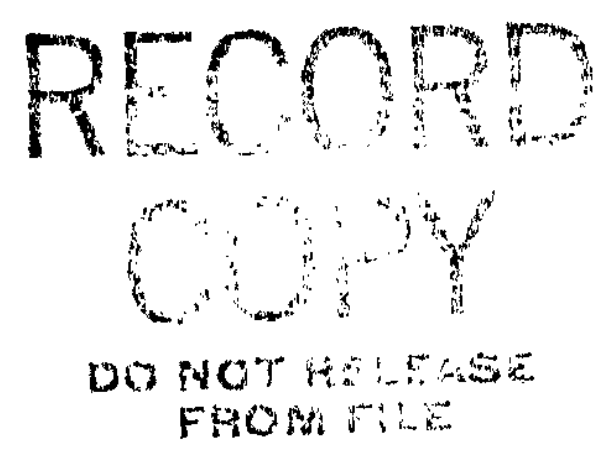

E. I. du Pont de Nemours \& Co.

Explosives Department - Atomic Energy Division

Technical Division - Savannah River Laboratory 
This report was prepared as an account of Government sponsored work. Neither the United States, nor the Commission, nor any person acting on behalf of the Commission:

A. Makes any warranty or representation, express or 1mplied, w1th respect to the accuracy, completeness, or usefulness of the information contalned in this report, or that the use of any information, apparatus, method, or process disclosed in this report may not infringe privately owned rights; or

B. Assumes any liabli1ties with respect to the use of; or for damages resulting from the use of any information, apparatus, method, or process disclosed in this report.

As used in the above, "person acting on behalf of the Commission" includes any employee or contractor of the commission to the extent that such employee or contractor prepares, handles or aistributes, or provides access to, any information pursuant to his employment or contract with the commission.

Printed in USA. Price \$0.25

Avaliable from the office of Technical Services

U. S. Department of Commerce

Washington 25, D. C. 
UNCLASSIFIED

$D P-169$

METALLURGY AND CERAMICS

RESIDUAL STRESSES IN THORIUM SLUGS

by

J. Walter Joseph, Jr. and John W. Walker

Pile Engineering Division

September 1956

E. I. du Pont de Nemours \& Co.

Explosives Department - Atomic Energy Division

Technical Division - Savannah River Laboratory

Printed for

The United States Atomic Energy Commission

Contract $\mathrm{AT}(07-2)-1$ 


\section{ABSTRACT}

Residual stresses of 2000 to $8000 \mathrm{psi}$ in compression were measured at the surface of cylindrical slugs of thorium. The stresses were measured by boring holes in the slugs and measuring the resulting surface deformation with strain gages. The tensile stresses that result from thermal gradients in the slugs during irradiation are partially counteracted by these residual stresses.

External Distribution according to TID-4500 (IIth Ed.) 


\section{INTERNAL DISTRIBUTION}

No. of Coples

(5) AEC, SROO

(l) R. M. Evans -

B. H. Mackey

(I) H. Worthington

(1) J. E. Cole -

M. H. Smith -

J. B. Tinker

(I) D. F. Babcock

(1) S. I. Winde

(I) J.A. Monier

I F. H. Endorf

I W. P. Overbeck

I) T. C. Evans

(1) A. A. Johnson

(1) P. A. Dahlen

I R. C. Holmes

(1) PRD File

(I) M. H. Wahl -

C. W. J. Wende -

W. M. Heston

(1) J. W. Croach

(1) P: H. Permar

(1) B. W. Dunnington

(I) J. T. Carleton

I R. R. Hood

(1) F. Welty

1 J.W. Walker

(I) J. W. Joseph

(15) TIS File

(I) TIS File Record Copy
Alken, S. C.

WIImington AED

$"$

Englneering Department

Savannah River Plant

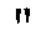

11

11

II

11

t1

Savannah RIver Laboratory

11

II

"1

II

11

II

$n$

11 


\section{$\underline{\text { Page }}$}

INTRODUCTION

SUMMARY

DISCUSSION

Fabrication of Thorium Slugs 4

Experimental Measurement of Residual Stress 5

Accuracy of Results . 7

Rolled Slugs 8

Extruded SIug 9

Region of Discontinuity 9

$\begin{array}{ll}\text { Can Stresses } & 10\end{array}$

BIBLIOGRAPHY II

APPENDIX

Detailed Description of Experimental Technique 21

Discussion of Standard Verification of Experimental Results

\section{LIST OF FIGURES AND TABLES}

Figure

Page

1 Thorium Slug During Residual Stress Measurements 12

2 Residual Stresses in SIug 0244-I-07 13

3 Residual Stresses in Slug 0244-1-21 14

4 Residual Stresses in SIug 0244-1-24 15

5 Residual Stresses in Slug $304 \quad 16$

6 Residual Stresses in Slug 1051-2-13 17

7 Measured Strains on Thorium Slugs I8

Table

I Residual Stresses in Thorium Slugs 19

II Slug Dimensions 20

III Strain Gage Locations 20 


\section{INTRODUCTION}

The heat generated in a thorium slug that is being irradiated causes the temperature at the axis to be higher than that at the surface of the slug. The resulting differential expansion sets up tensile stresses at the surface of the slug. In addition to these thermal stresses, a slug may be expected to contain residual stresses that are introduced by plastic deformation of the metal during fabrication. This report describes the evaluation of residual stresses in thorium slugs.

\section{SUMMARY}

The residual stresses at the surfaces of the bare slugs tested were 5000 to 8000 psi for rolled thorium, 3500 psi for extruded thorium, and $2000 \mathrm{psi}$ for rolled thorium that had been partially annealed. All surface stresses were compressive. More complete data are presented in Table I. If the center of a slug is hotter than its surface, the thermal stresses will be tensile at the slug surface. Residual compressive stresses are desirable since they oppose the thermal stress. Residual stresses in slug cans and end caps were nil.

The Sachs method of measuring residual stresses was refined to take advantage of current machining practices and the use of bonded-wire gages for strain measurement. This method consists of removing metal from the center of the slug and measuring the surface strains resulting from the relief of stresses contained in the portion that is bored out. The data were analyzed by graphical differentiation. Mathematical analysis shows that there is no rigorous method of verifying analytically the accuracy of the residual stresses obtained by the Sachs method. However, the theory is exact and comparisons with less versatile methods indicate that the Sachs technique is accurate for determining residual stresses in cylinders.

\section{DISCUSSION}

FABRICATION OF THORIUM SLUGS

Residual stresses in thorium slugs are caused by nonuniform plastic deformation of the slug during the fabrication processes. This deformation may result from the rolling, extruding, or hotpressing steps of manufacture. Rods of induction-melted or arc-melted thorium are formed by rolling or extruding. Thorium prepared by arc melting has greater purity, fewer inclusions, and more ductility than material made by the older process. 
EXPERIMENTAL MEASUREMENT OF RESIDUAL STRESS

In 1919 Mesnager( $(9)$ expanded the earlier work of Heyn and Bauer $(6)$ and developed an experimental method for analyzing residual stresses in cylinders and tubes. The method consists of boring axial holes of increasing size in a rod, and measuring the resulting surface strains, or deformations, at the surface of the rod.

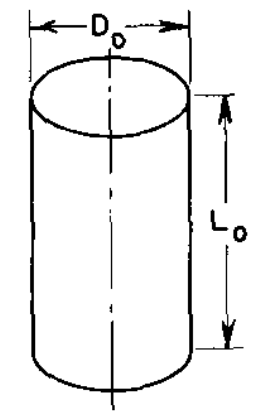

BEFORE BORING

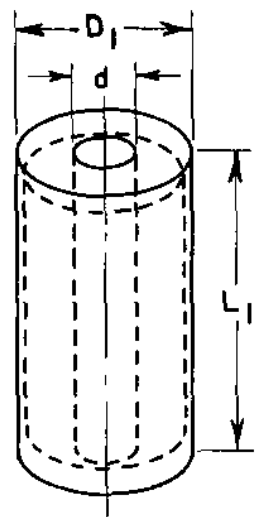

AFTER BORING

\section{SCHEMATIC REPRESENTATION OF BORING-OUT METHOD}

Consider the test cylinder above. Before boring, the internal stresses are at equilibrium so that there are no changes in the dimensions $\mathrm{D}_{0}$ and $\mathrm{L}_{0}$. A hole of diameter d bored through the slug will relieve the stresses that were present in the material that is drilled out. A stress unbalance now exists in the remaining material, and the slug will deform elastically to reach the new equilibrium dimensions $D_{1}$ and $L_{1}$. The measured changes in these dimensions may be substituted into formulas derived from elastic theory for thickwalled cylinders to solve for the longitudinal, tangential, and radial stresses in the material that was removed. The machining procedure is repeated for holes of increasing size to obtain the stress distribution in the cylinder. Sachs(1I) greatly simplified the calculations, and the method, commonly known as the Sachs boring-out method, is widely accepted today. 2$)(3,(7)(8)(12)$ The Sachs method recognizes all three principal stresses, defined $(13)$ as the stresses normal to planes of zero shear, and assumes only that the stress distribution is symmetrical around the slug axis. This report presents the residual stresses in representative thorium slugs as measured by means of a modified Sachs technique.

The first step in the experimental analysis was to strip off part of the aluminum cladding in a concentrated sodium hydroxide solution. For a detalled description of the experimental technique and equipment, refer to the Appendix. SR-4 strain gages of bonded resistance wire (10) were cemented to the bare thorium parallel to the axis and around the circumference of the slug as is shown below. 


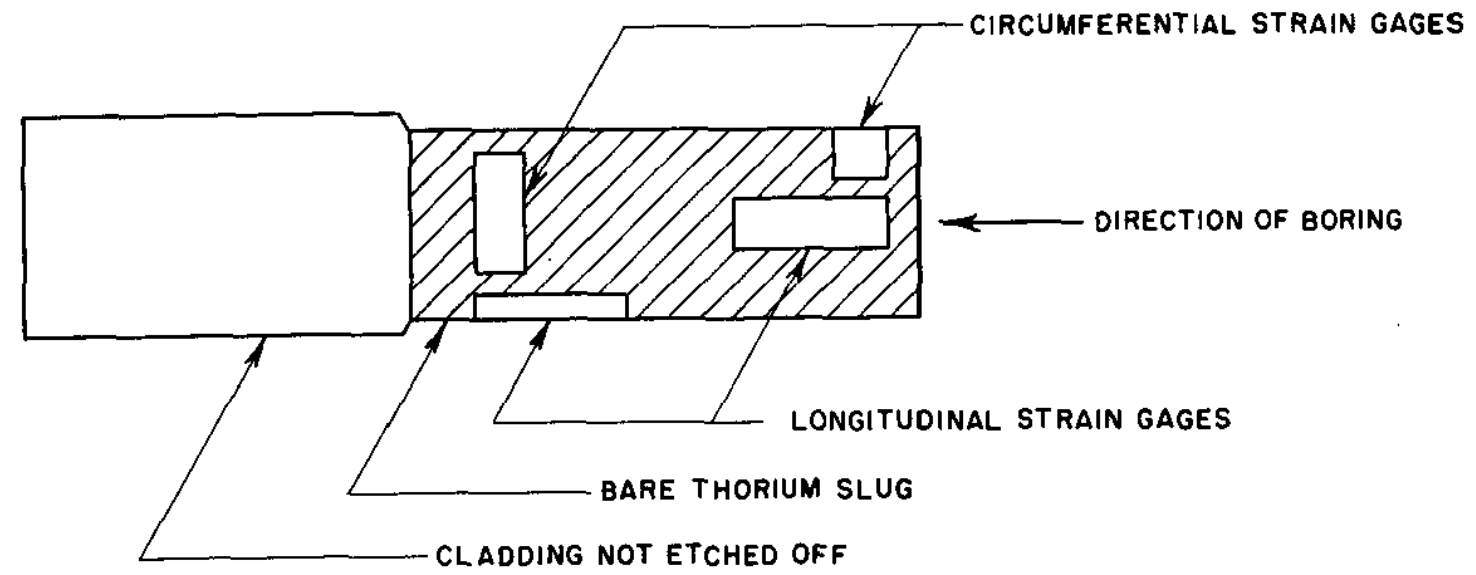

TYPICAL PREPARED SLUG

The etching step was found to be necessary since strains measured by SR-4 gages on the cladding of Slug 0244-1-2l were much lower than those measured on the bare thorium. A complete description of dimensions and strain gage locations for each slug is included in Tables II and III. The strain gages were protected from the coolant used during the machining operation by a coating of petrosene wax.

The machining was performed on a horizontal miliing machine. The slug was clamped to the bed as is shown in Figure 1, and a drill or boring bar was chucked in the spindle of the machine. This technique represents a considerable improvement over the usual method (7)(8) in which the specimen is rotated in a lathe while the tool is held stationary. In the conventional method, provisions must be made to disconnect the strain gage leads while the specimen is being rotated and to reconnect these leads when readings are taken. The advantages realized by fixing the specimen and rotating the tool are (1) the strain gage leads are permanent, (2) changes in contact resistances caused by connecting and disconnecting the leads are eliminated, (3) continuous reading of the strain gages during the boring operation is possible, and (4) the time required to perform the experiment is decreased. The advantages of clamping the slug and rotating the tool were discussed previously by Dodd (4), but the importance of his work was not recognized in literature published in the United States.

A dummy gage was located near the test gages to compensate the Wheatstone bridge circuit for changes in room temperature. A $0.177-$ inch hole was then drilled along the slug axis to a depth of at least one slug diameter past the farthest gage. Continuous strain gage readings were taken on a portable strain indicator during the drilling operation to assure that high temperatures caused by drill friction were not damaging the gages. The strain gage observations were continued after the drill was removed from the slug. When the slug cooled down to room temperature, the gage readings were recorded. 
This procedure was repeated in increasing diameter increments of $1 / 32$ inch until the remaining thin shell cracked.

Strain data from the gages midway along the slug length were converted into stresses by the equations derived by Sachs (11). The longitudinal strain, $\epsilon_{\mathrm{L}}$, and the tangential strain, $\epsilon_{\mathrm{T}}$, were assembled into the parameters $\Lambda$ and $\theta$, defined by

$$
\begin{aligned}
& \Lambda=\epsilon_{\mathrm{L}}+\mu \epsilon_{\mathrm{T}} \\
& \theta=\epsilon_{\mathrm{T}}+\mu \epsilon_{\mathrm{I}}
\end{aligned}
$$

where $\mu$ is Poisson's ratio for thorium. These parameters were plotted versus the cross-sectional area, $A$, of the metal that was removed. By graphical differentiation, plots of $d \Lambda / d A$ and $d \theta / d A$ versus $A$ were derived from the curves of $\Lambda$ and $\theta$ versus $A$. The three principal stresses were then calculated from the following relations.

$$
\begin{aligned}
& \sigma_{L}=\frac{E}{1-\mu^{2}}\left[\left(A_{0}-A\right) \frac{d \Lambda}{d A}-\Lambda\right] \\
& \sigma_{T}=\frac{E}{1-\mu^{2}}\left[\left(A_{0}-A\right) \frac{d \theta}{d A}-\left(\frac{A_{0}+A}{2 A}\right) \theta\right] \\
& \sigma_{R}=\frac{E}{1-\mu^{2}}\left[\left(\frac{A_{0}-A}{2 A}\right) \theta\right]
\end{aligned}
$$

where $\sigma_{\mathrm{L}}, \sigma_{\mathrm{T}}, \sigma_{\mathrm{R}}=$ longitudinal, tangential, and radial residual stresses at the radius corresponding to the boredout area, A

$E=$ Young's modulus

$A_{0}=$ original cross-sectional area of slug

$A=$ bored-out cross-sectional area

Buhler(3) derived similar equations for the case of metal machined from the outside surface of a cylinder.

ACCURACY OF RESULTS

There is no analytical method of verifying the accuracy of the residual stresses obtained by the Sachs boring-out technique. The standard method of verifying these stresses is to compare them with the following criteria: (1) The plot of longitudinal stress versus cross-sectional area must have equal areas in tension and compression; (2) the plot of tangential stress versus radius must have equal areas under tension and compression; and (3) the radial stress is zero at the surface and equal to the tangential stress at the center of the slug. It is shown in the Appendix that the above criteria are not verifications of the accuracy of the measured stresses. The stresses, regardless of their accuracy, must conform to these criteria because of the conditions used in deriving the stress equations. Indications of the accuracy of the sachs method 
are found in the works of Buhler(3) and Dodd(4). Buhler measured the residual stresses near the axis of a solid cylinder by the standard Sachs method. After boring out approximately half of the cross section, he cemented strain gages to the interior surface and finished the stress analysis by turning down the outside of the cylinder while measuring the resulting strains on the inside surface. The residual stress curves plotted from these two operations were in excellent agreement. This agreement shows that cold work during the boring operation caused negligible errors in the test results. Dodd measured the residual surface stresses on several duralumin billets by using an $\mathrm{X}$-ray technique developea by Frommer and Lloyd ${ }^{(5)}$. He then obtalned the stress distribution in the billets by the sachs method. The surface stresses obtained by these two methods had an average difference of 10 per cent and a maximum difference of 27 per cent. The results of the experiments of Buhler and Dodd are important because they provide the only evidence of the accuracy of the Sachs method. In the absence of an analytical proof of the validity of data obtained by this method, it is necessary to rely on the results of these experiments to define the accuracy of the data. The two experiments agree in indicating that the Sachs method will give results that are satisfactory for most engineering applications.

ROLLED SLUGS

The residual stresses in three rolled slugs of thorium, 1.0 inch in diameter, were measured. These siugs were from the same billet and section. Slug dimensions are included in Table II. Two of the slugs (0244-1-07 and 0244-1-21) were canned and stripped prior to testing. The residual stresses in these slugs are plotted in Figures 2 and 3 as functions of slug radius. The agreement between the shapes of these curves is extremely close. The stress curves represent average values and are not valid for the ends of the slugs. The ends are necked down (see Table II) during the canning process, and approximate calculations show that stresses near the ends may be as much as 40 per cent greater than the average stresses. The residual stress curves of Figures 2 and 3 are smoothed to minimize the effects of abrupt discontinuities that occurred at a radius of 0.16 to 0.19 inch in Slug $0244-1-21$ and at a radius of 0.22 to 0.26 inch in Slug 0244-1-07. These discontinuities are apparent in the plots of Figure 7. The extreme changes in measured strain make it impossible to determine accurately the shape of the stress curves in these regions.

The effect of annealing on residual stresses was studied with the third 1.0-inch slug (0244-1-24). The annealing process consisted of heating the canned and stripped slug at $1000^{\circ} \mathrm{C}$ in an argon atmosphere for one hour and then cooling it in air. The residual stress distribution in this slug is shown in Figure 4. Apparently, the annealing process was not completely, successful since full annealing would eliminate the residual stresses $(4)$. In this siug the annealing process reduced the residual stresses to between 5 and 40 per cent of the values measured for the other two slugs. The region of discontinuity that was found in the canned and stripped slugs appeared in the annealed slug at a radius of 0.26 inch (see 
Figure 7). Although the magnitude of this discontinuity was reduced by the annealing process, the discontinuity was not completely eliminated. Therefore, the stress curves in Figure 4 required considerable smoothing in this region.

The residual stresses in a larger slug (304) are plotted in Figure 5. This slug was 1.7 inches in diameter after decanning. Dimensions of the slug are tabulated in Table II. The interior stresses in the large slug were considerably less than the interior stresses in the small slugs of similar material, but the surface stresses were approximately the same. The residual stress data for this slug plotted into a smooth curve, although a discontinuity in the measured strain occurred at a radius of 0.20 inch (see Figure 7 ).

\section{EXTRUDED SLUG}

The residual stresses in an extruded slug of thorium (1051-2-13) are plotted in Figure 6. This slug had been canned and stripped prior to testing. Complete dimensions of this I.O-inchdiameter slug are tabulated in Table II. The stresses in this slug were between 18 and 80 per cent of the stresses in similar slugs of rolled material. A region of discontinuity appeared in the slug at a radius of 0.26 inch. This region is apparent in the data of Figure 7. The discontinuity made the exact shape of the stress curves impossible to define in this region.

\section{REGION OF DISCONTINUITY}

The data for all five of the slugs are consistent in showing that a region of discontinuity exists in clad thorium slugs between radii of 0.16 and 0.26 inch. In view of this consistency, it seems very improbable that the effect is caused by faulty technique. This region may be indicative of one or more of the following phenomena:

1. A preferred orientation for cracks or inclusions - The plots of measured strain versus radius (Figure 7) might be interpreted as indicating an essentially free surface at the region of discontinuity. A preferred orientation for cracks or inclusions in this region could produce such a free surface.

2. Nonuniform grain size - This condition could occur during cooling from the melting, extruding, rolling, or hot-bonding . steps of manufacture. Full annealing would eliminate this condition. When Slug 224-1-24 was partially annealed, the magnitude of its discontinuity was reduced. This indicates that nonuniform grain size might have been the cause of the region of discontinuity.

3. Chemical segregation - The possibility of chemical segregation within the slug is not too remote to be considered.

4. Nonuniform texture - The theory that the grain orientation is not uniform along the slug radius seems to be most promising. The phenomenon would probably be combined with nonuniform grain size. 


\section{CAN STRESSES}

An investigation was made to determine the residual stresses in the aluminum can and end cap of a clad thorium slug. A rosette of three SR-4 strain gages located on $120^{\circ}$ centers was cemented to the end cap and two SR-4 gages were cemented to the can in axial and circumferential planes. Residual stresses in the can and end cap were relieved by drilling $1 / 4$-inch holes through the aluminum at the intersections of the strain gage axes. Can stresses were further relieved by using a slitting saw to cut completely around the gages. The drawing below illustrates these procedures.

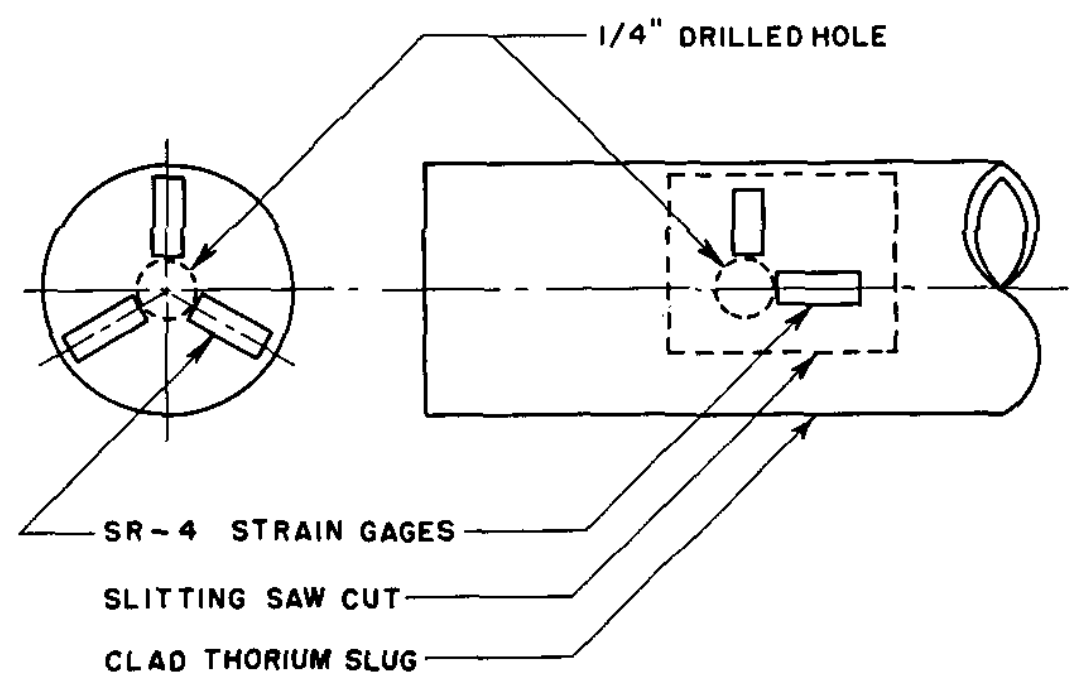

\section{MEASUREMENT OF CAN AND END CAP STRESSES}

Care was taken not to cut into the thorium during these operations. The difference between strain gage readings before and after the stress-relieving operations was essentialiy zero. This investigation indicates that can and end cap stresses were nil.

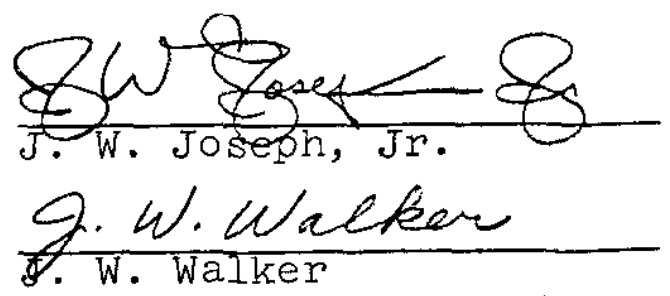

Pile Engineering Division 


\section{BIBLIOGRAPHY}

1. Baldwin-Lima-Hamilton Corp. How to Apply SR-4 Strain Gages, Bulletin 279-B, Philadelphia, 1951.

2. Barrett, C. S. "A Critical Review of Various Methods of Residual Stress Measurement", Experimental Stress Analysis, v.2, n.1, 1944, pp. 148-149.

3. Buhler, H. "Complete Determination of the State of Residual Stress in solid and Hollow Metal Cylinders", Residual stresses in Metals and Metal Construction, edited by W. R. Osgood, New York: Reinhold Publishing Corp. (1954) pp. 305-329.

4. Dodd, R. A. "Some Observations on the Determination of Residual Stresses in Cylindrical Metal Bodies by Sachs' Boring Method", Metallurgia, v.45, March 1952, pp. 109-114.

5. Frommer, L. and Lloyd, E. H. "The Measurement of Residual Stresses in Metals by the X-Ray Back-Reflection Method, with Special Reference to Industrial Components in Aluminum Alloys", Institute of Metals Journal, v.11, March 1944, pp. 91-124.

6. Heyn, E. and Bauer, O. "Stresses in Boiler Plates", Stahl und Eisen, v.31, 1911, pp. 760-765.

7. Horger, 0. J. "Residual Stresses", Handbook of Experimental Stress Analysis, edited by M. Hetenyi, New York: John Wiley and Sons (1950) pp. 461-464.

8. Lynch, J.J. Residual Stress Measurements, Cleveland: American Society for Metals (1952) pp. 48-54.

9. Mesnager, M. "A Method for Determining the Stresses Existing in a Cylinder", Comptes Rendus, v.169, 1919, pp. 1391-1393.

10. Perry, C. C. and Lissner, H. R. The Strain Gage Primer, New York: McGraw-Hill Book Co. (1955).

11. Sachs, G. "Detection of Internal Stress in Rods and Tubes", Zeitschrift für Metallkunde, v.19, 1927, pp. 352-357.

12. Sachs, G. and Van Horn, K. R. Practical Metallurgy, Cleveland: American Society for Metals (195I) pp. 178-180.

13. Timoshenko, S. and Goodier, J. N. Theory of Elasticity, New York: McGraw-Hill Book Co. (1951) p. 14. 


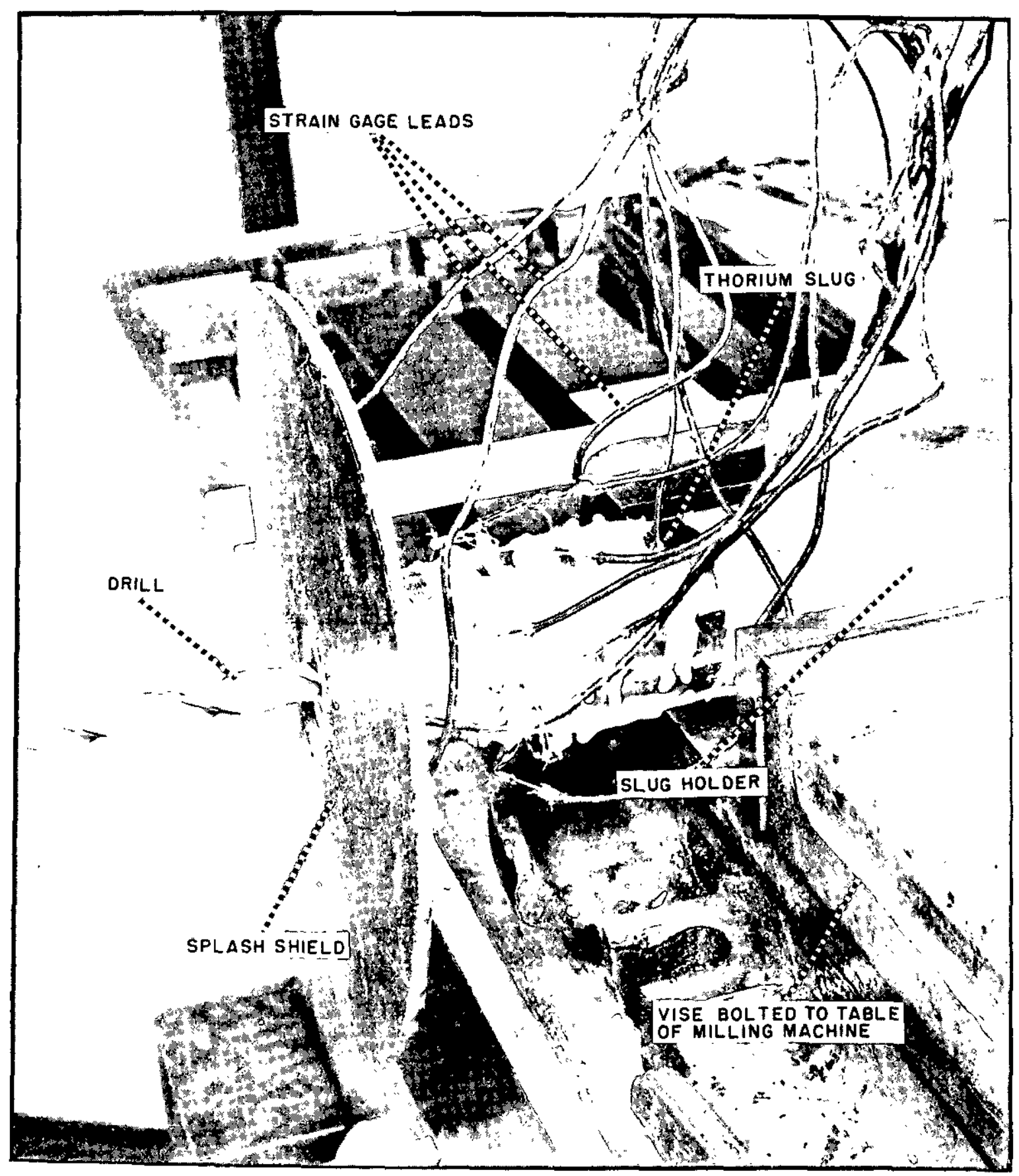

THORIUM SLUG DURING RESIDUAL STRESS MEASUREMENTS 


\section{FIGURE 2}

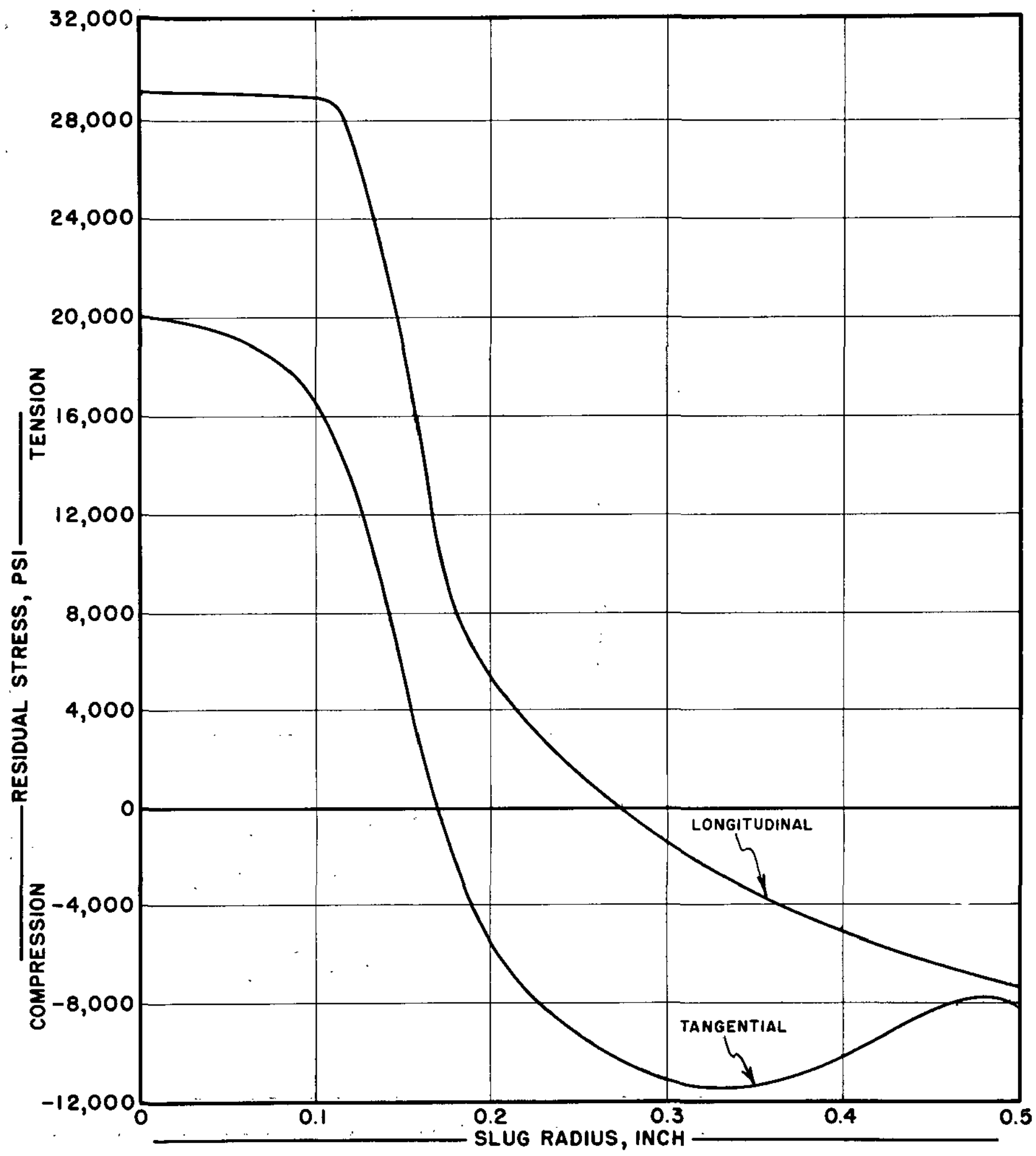

RESIDUAL STRESSES IN SLUG 0244-1-07 ROLLED THORIUM - CANNED AND STRIPPED 


\section{FIGURE 3}

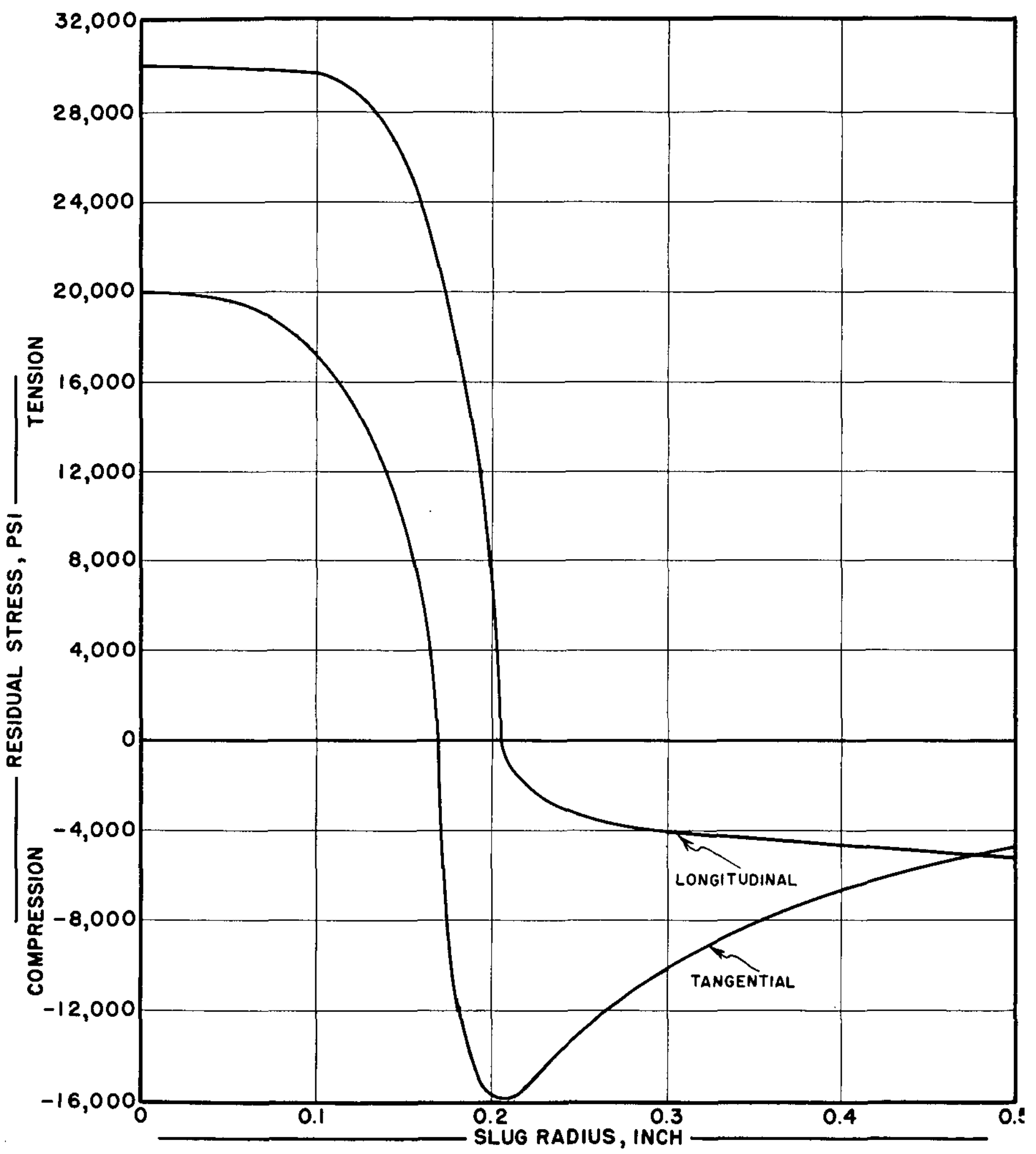

RESIDUAL STRESSES IN SLUG 0244-|-2| ROLLED THORIUM - CANNED AND STRIPPED 


\section{FIGURE 4}

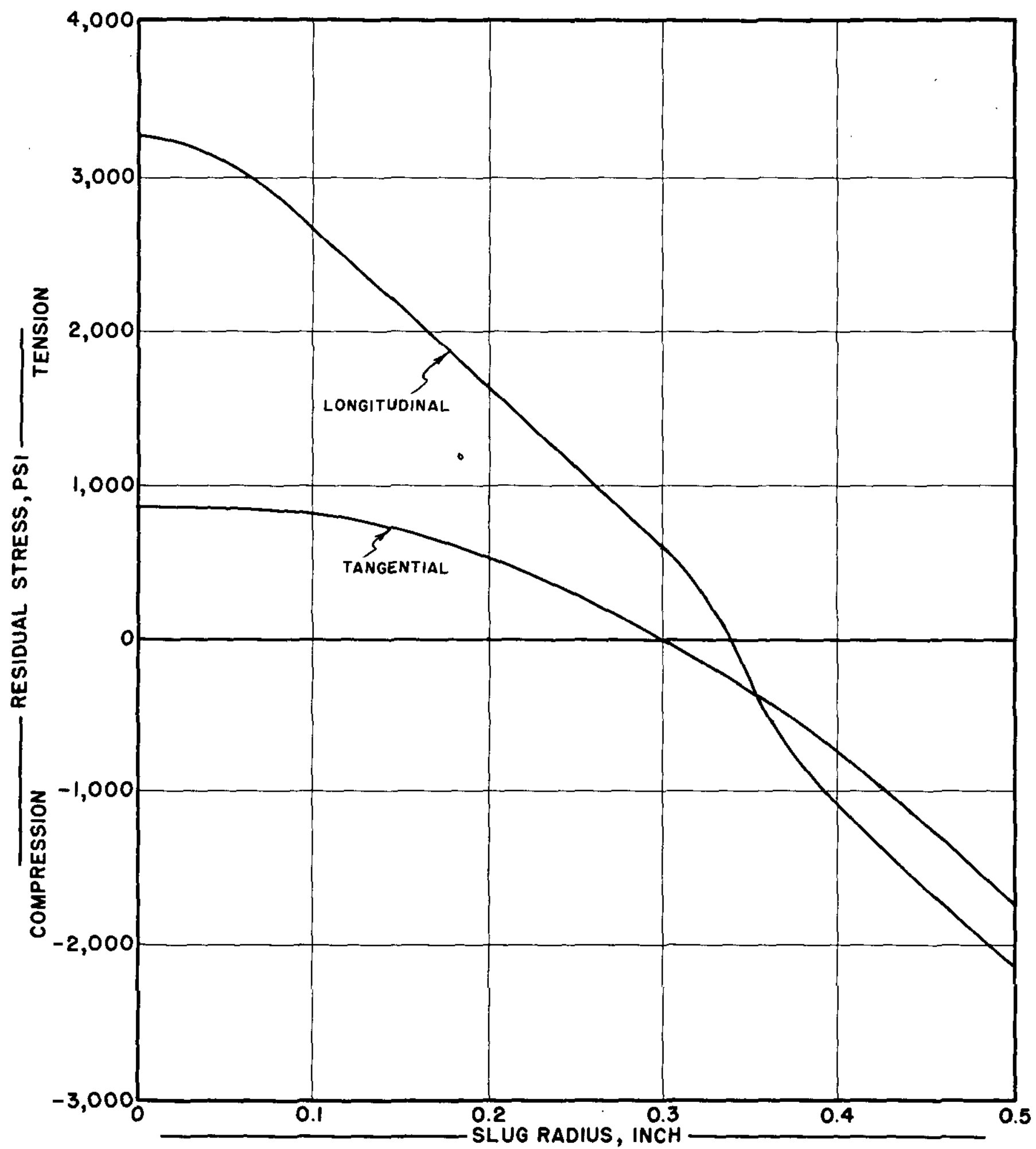

RESIDUAL STRESSES IN SLUG O244-1-24

ROLLED THORIUM-CANNED, STRIPPED, AND ANNEALED 


\section{FIGURE 5}

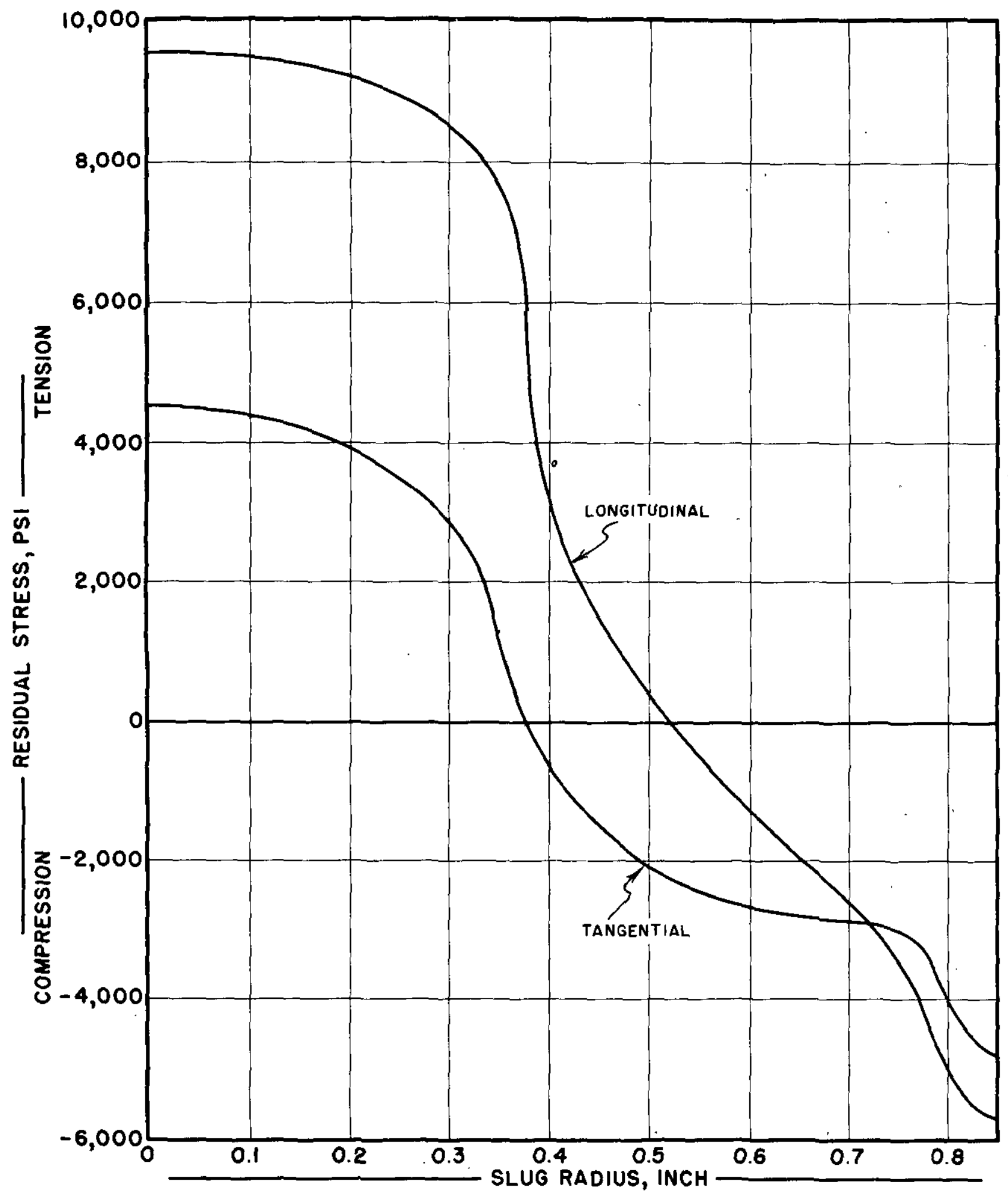

RESIDUAL STRESSES IN SLUG 304

ROLLED THORIUM - CANNED AND STRIPPED

$-16-$ 


\section{FIGURE 6}

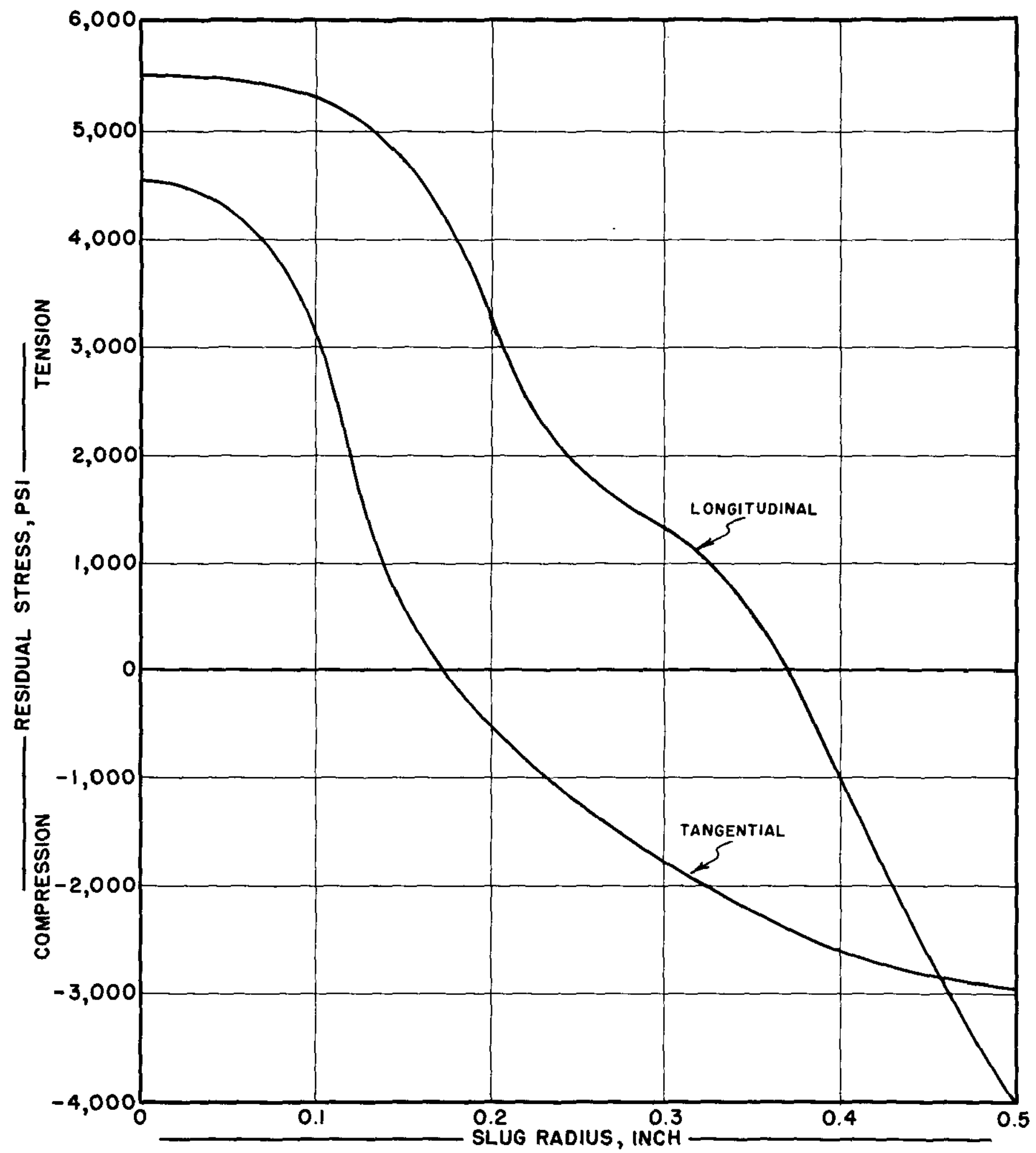

RESIDUAL STRESSES IN SLUG $1051-2-13$

EXTRUDED THORIUM-CANNED AND STRIPPED

$-17-$ 


\section{FIGURE 7}

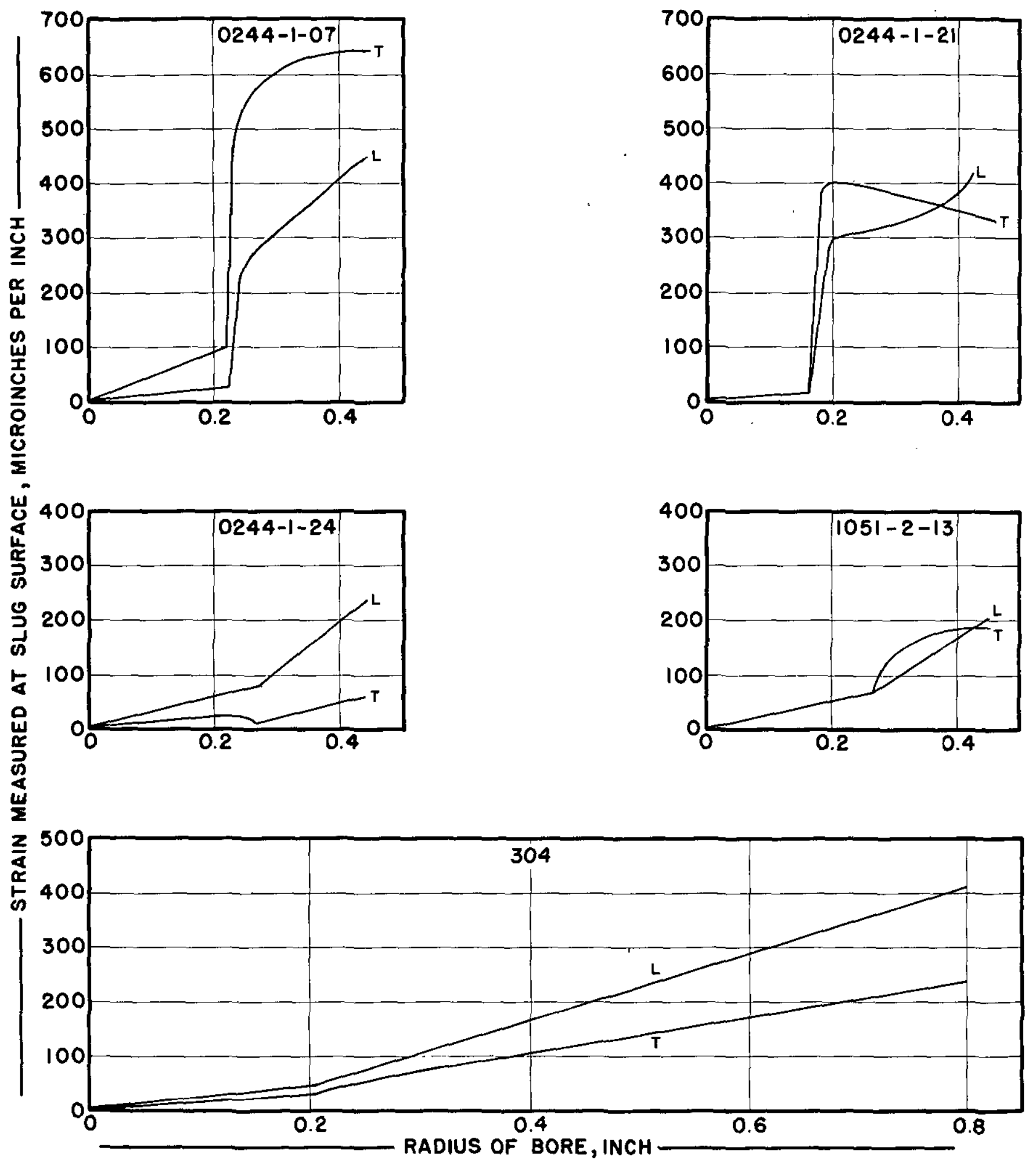

MEASURED STRAINS ON THORIUM SLUGS

( $T=$ TANGENTIAL , L = LONGITUDINAL)

$$
-18-
$$




\section{TABLE I}

\section{RESIDUAL STRESSES IN THORIUM SLUGS}

\begin{tabular}{|c|c|c|c|c|c|c|}
\hline \multirow[b]{2}{*}{ SLUG NO. } & \multirow[b]{2}{*}{ FORMING PROCESS } & \multirow{2}{*}{$\begin{array}{l}\text { SIUG } \\
\text { DIAM., } \\
\text { in. } \\
\end{array}$} & \multicolumn{4}{|c|}{ RESIDUAL STRESSES, psi } \\
\hline & & & AXIS & SURFACE & AXIS & SURFACE \\
\hline $0244-1-07$ & Rolled & 1.00 & 29,000 & -8000 & 20,000 & -8000 \\
\hline $0244-1-21$ & Rolled & 1.00 & 30,000 & -5000 & 20,000 & -5000 \\
\hline $0244-1-24$ & Rolled-Annealed & 1.00 & 3,000 & -2000 & 1,000 & -2000 \\
\hline 304 & Rolled & 1.70 & 10,000 & -6000 & 5,000 & -5000 \\
\hline $1051-2-13$ & Extruded & 1.00 & 6,000 & -4000 & 5,000 & -3000 \\
\hline
\end{tabular}

Note: All slugs were canned and stripped prior to testing. Positive stresses are tensile; negative stresses are compressive. 


\section{TABLE II}
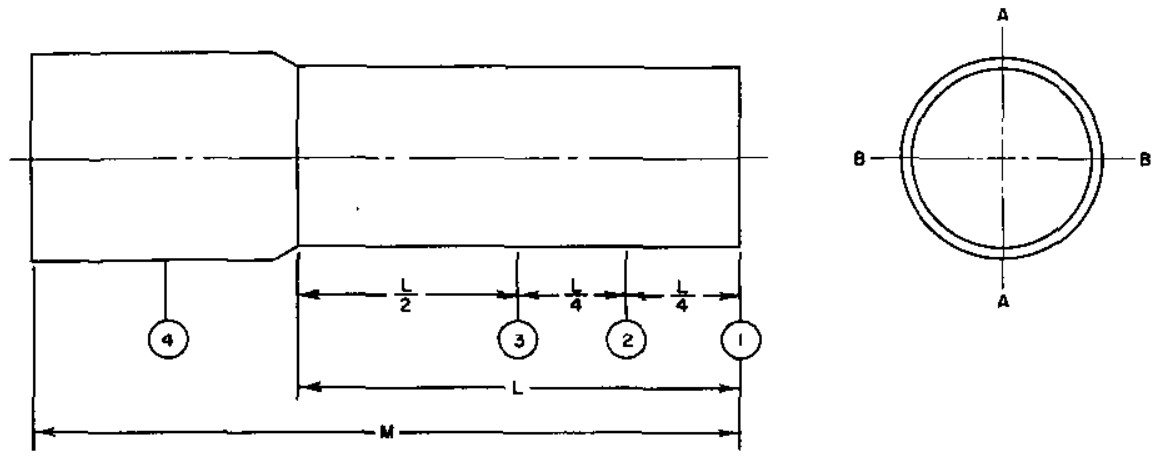

SLUG DIMENSIONS

Diameters, inches

\begin{tabular}{|c|c|c|c|c|c|c|c|c|c|c|}
\hline \multirow{3}{*}{ Slue No. } & \multirow{3}{*}{$I$, in. } & \multirow{3}{*}{$M$, in. } & \\
\hline & & & \multicolumn{2}{|c|}{ At 1} & \multicolumn{2}{|c|}{ At 2} & \multicolumn{2}{|c|}{ At 3} & \multicolumn{2}{|c|}{ At 4 (Can) } \\
\hline & & & $\mathrm{AA}$ & $\mathrm{BB}$ & $\mathrm{AA}$ & $\mathrm{BB}$ & $\overline{A A}$ & $B B$ & $A A$ & $\overline{\mathrm{BB}}$ \\
\hline $0244-1-07$ & $2-9 / 16$ & $5-3 / 4$ & 0.984 & 0.986 & 1.004 & 1.005 & 1.006 & 1.007 & 1.087 & 1.087 \\
\hline $0244-1-21$ & $2-29 / 32$ & $-\cdots--$ & 0.988 & ----- & 1.001 & ----- & 1.005 & $---\infty$ & 1.090 & 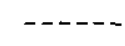 \\
\hline $0244-1-24$ & $5-11 / 16$ & $5-11 / 16$ & 0.986 & 0.986 & 0.995 & 0.995 & 0.996 & 0.997 & $\ldots$ & $-\ldots$ \\
\hline 304 & $3-3 / 4$ & $7-3 / 16$ & 1.683 & 1.683 & 1.698 & 1.698 & 1.700 & 1.705 & 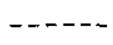 & $\ldots-n$ \\
\hline $1051-2-13$ & $2-11 / 16$ & $5-3 / 4$ & 0.991 & 0.992 & 1.005 & 1.006 & 1.007 & 1.007 & 1.088 & 1.091 \\
\hline
\end{tabular}

\section{TABLE III}

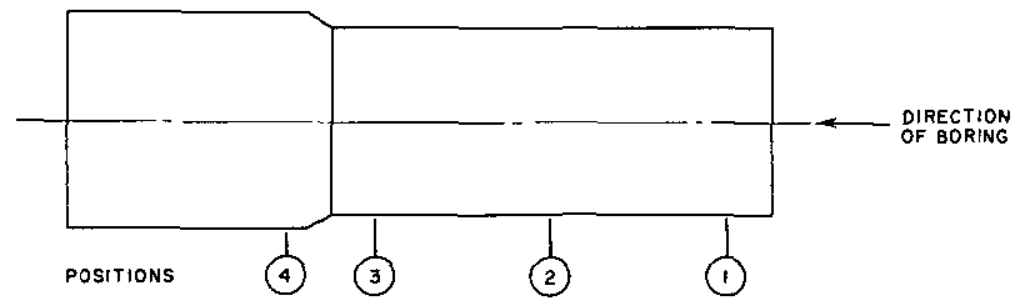

STRAIN GAGE LOCATIONS

\begin{tabular}{|c|c|c|c|c|c|}
\hline Slug No. & Gage Type (1) & Total Numbe & Lon & $\begin{array}{l}\text { lal } \\
\text { Pos }\end{array}$ & \\
\hline & & (1) & (2) & (3) & (4) \\
\hline $0244-1-07$ & $A-5-1$ & $2^{(2)}$ & 2 & 2 & - \\
\hline $0244-1-21$ & $A-5-1$ & - & - & 4 & 2 \\
\hline $0244-1-24$ & $A X-5$ & - & 2 & 2 & - \\
\hline 304 & $A X-5$ & 2 & 2 & 6 & - \\
\hline $1051-2-13$ & $A X-5$ & 2 & 2 & 2 & - \\
\hline
\end{tabular}

(1) All gages were SR-4 strain gages manufactured by the Baldwin-Lima-Hamilton Corp. of Philadelphia. Type numbers are Baldwin designations.

(2) The two gages at this position were A-7's. 


\section{APPENDIX}

\section{DETAILED DESCRIPTION OF EXPERIMENTAL TECHNIQUE}

\section{Slug Preparation}

A clad thorium slug was decanned for slightly over half its length by standing it upright in an etchant solution of 26 per cent sodium hydroxide. The 0.040-inch aluminum can was etched off in four to eight hours by this solution. Measurements of the slug were made with a micrometer. The slug was then chucked in a lathe and rotated while the thorium surface was dressed with fine emery paper. Strain gages were attached to the bare slug by the technique recommended by the Baldwin Corporation(1), using SR-4 precoat and cement. Gages of Types A-5-1, A-7, and AX-5 were used (see Table III). The AX-5 gages are especially suited to this experiment because of their two-element rosette construction. The gages were tested with an ohmmeter to insure that each gage had a resistance of 120 ohms and that there were no short circuits between the gages and the slug. One wire from each gage was then soldered to a common lead that was attached to one "active gage" terminal of a Baldwin SR-4 Model MA Portable Strain Indicator. The second wire from each gage was connected to the properly numbered active gage terminal of a Baldwin SR-4 Twenty-Point Switching Unit. A single compensating gage was connected between the indicator and the switching unit to balance all the test gages against changes in ambient air temperature. After all the gage connections on the slug were soldered, the gages were protected from moisture by a coat of Petrosene wax. The clad end of the slug was then slipped into a holder prepared from a block of aluminum. The holder was bored to the outside diameter of the clad slug and slit so that gripping the flat sides of the holder exerted a clamping action around the slug. The clamp was at least one slug diameter back from the nearest strain gage so that the clamping did not introduce extraneous stresses in the slug. This arrangement corrects one objectionable feature in the technique proposed by Dodd(4), in which the cylinders were clamped at both ends and the strains were measured at the center close to the clamps. The slug and holder were clamped in a vise fixed to the table of a Gorton Model 2-28B Horizontal Milling Machine. A fiber splash guard was slipped loosely over the end of the slug to prevent coolant splash from short-circuiting the strain gage wires. A photograph of the test arrangement is included as Figure 1 .

\section{Machining Procedure}

The center of the slug was accurately located with a dial indicator and center-bored. Readings of all strain gages were taken to establish the unrelieved condition. A 0.177-inch hole was drilled along the slug axis. Coolant was used on the drill while it was cutting. Continuous strain gage readings were taken on the gage showing the highest strain. During the drilling operation, the strain gage readings increased due to (1) the relief of stresses in the metal being removed, and (2) increasing slug temperature caused by drill friction. When the gage reading had increased 150 micro- 
inches per inch, the drill was stopped and was backed out of its hole. This step was taken to eliminate the possibility of strain gage damage by high temperatures or thermal stresses induced by high temperatures. After the drill was removed from the slug, the gage readings began to drift downward. After two or three minutes this drift was negligible, as the temperature of the test gages approached the temperature of the dummy gage; the drill was then reinserted. This procedure was continued until the drilled hole reached a depth of at least one slug diameter past the farthest strain gage. The drill was then backed out and the coolant was shut off. After about ten minutes the gage readings ceased to drif.t, and all gage readings were recorded. The above procedure was then repeated with a 0.209 -inch drill. A I/4inch drill was next used, followed by drills increasing in 1/32-inch increments. For some of the slugs, a boring bar was used at the larger diameters. The bar was incapable of as heavy a cut as a drill but had the advantage of providing less heating. Successively larger holes were drilled until the remaining thin shell of the slug cracked during the drilling operation. This failure occurred when the shell thickness was between 0.005 and 0.065 inch.

\section{Data Analysis}

The strains measured by the gages midway along the slug length at each step in the boring-out operation were assembled into the parameters $\Lambda$ and $\theta$, defined by

$$
\begin{aligned}
& \Lambda=\epsilon_{\mathrm{I}}+\mu \epsilon_{\mathrm{T}} \\
& \theta=\epsilon_{\mathrm{T}}+\mu \epsilon_{\mathrm{I}}
\end{aligned}
$$

where $\epsilon_{L}$ is the measured Iongitudinal strain, $\epsilon_{\mathrm{T}}$ is the measured tangential strain, and $\mu$ is Poisson's ratio (taken as 0.26 for thorium). These parameters were plotted against the area of the drilled-out cross section to give smooth curves. Typical curves of this type are shown on page 24. Graphical differentiation of the curves as shown below yielded the slope curves d $\Lambda / d A$ versus $A$ and $\mathrm{d} \theta / \mathrm{dA}$ versus A.
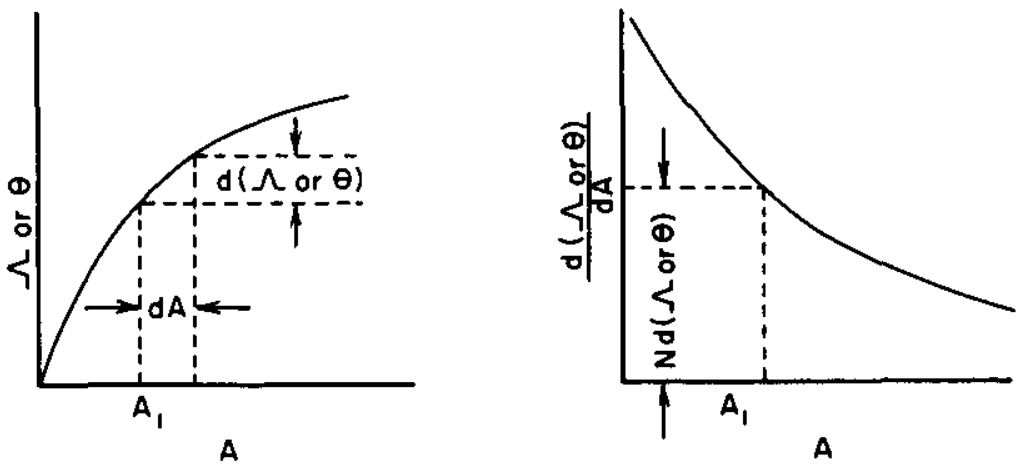
The abscissas of the curves of $(\Lambda$ or $\theta$ ) versus $A$ were divided into equal segments $\mathrm{dA}$ such that

$$
N \cdot d A=I
$$

where $N$ is some convenient integer.

The change in $(\Lambda$ or $\theta)$ in the interval dA was $\alpha(\Lambda$ or $\theta)$. The relation for a point on the slope curve $a(\Lambda$ or $\theta)$ versus $d A$ is as follows:

$$
\begin{aligned}
\frac{d(\Lambda \text { or } \theta)}{d A} & =\frac{a(\Lambda \text { or } \theta)}{d A} \cdot \frac{N}{N} \\
& =\frac{N \cdot d(\Lambda \text { or } \theta)}{1} \\
& =N \cdot d(\Lambda \text { or } \theta)
\end{aligned}
$$

The distance $d(\Lambda$ or $\theta)$ was laid off $N$ times with dividers at an abscissa equal to $A_{1}+1 / 2$ dA to locate a point on the slope curve. The slope curves were obtained by connecting points plotted in this manner. The curves were smooth and continuous except at regions where $\Lambda$ and $\theta$ changed abruptly. Typical slope curves are shown on page 24 .

Values of $\Lambda, \theta, d \Lambda / d A$, and $d \theta / d A$ from the above curves were inserted into the following expressions to solve for the principal stresses at values of A:

$$
\begin{aligned}
& \sigma_{L}=\frac{E}{1-\mu^{2}}\left[\left(A_{O}-A\right) \frac{d \Lambda}{d A}-\Lambda\right] \\
& \sigma_{T}=\frac{E}{1-\mu^{2}}\left[\left(A_{O}-A\right) \frac{d \theta}{d A}-\left(\frac{A_{O}+A}{2 A}\right) \cdot \theta \cdot\right] \\
& \sigma_{R}=\frac{E}{1-\mu^{2}}\left[\left(\frac{A_{0}-A}{2 A}\right) \theta\right]
\end{aligned}
$$

where

$$
\begin{aligned}
\sigma_{\mathrm{L}}, \sigma_{\mathrm{T}}, \sigma_{\mathrm{R}}= & \begin{array}{l}
\text { longitudinal, tangential, and radial residual } \\
\text { stresses at the radius corresponding to the } \\
\\
\text { bored-out area, } \mathrm{A}
\end{array} \\
\mathrm{E}= & \text { Young's modulus } \\
\mathrm{A}_{0}= & \text { original cross-sectional area of slug } \\
\mathrm{A}= & \text { bored-out cross-sectional area }
\end{aligned}
$$

When the data derived from these equations were plotted as functions of slug radius, the residual stress patterns of Figures 2 through 6 were obtained. 

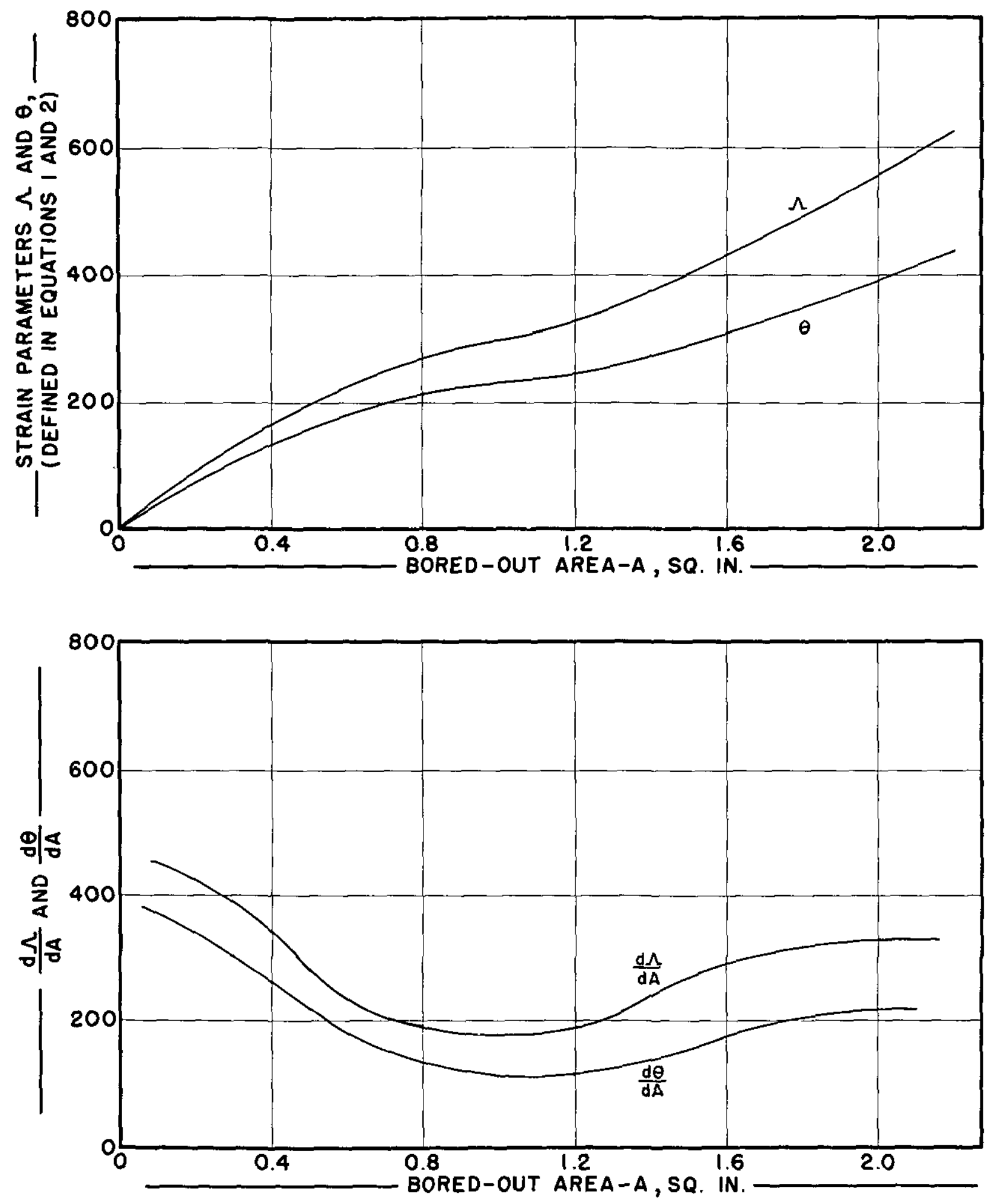

STRAIN PARAMETER DATA FROM SLUG 304 
The standard method of evaluating the accuracy of residual stresses obtained by the Sachs boring-out technique is to compare them with the following criteria which satisfy equilibrium force and moment balances in the slug: (I) The plot of longitudinal stress versus cross-sectional area must have equal areas in tension and compression. (2) The plot of tangential stress versus radius must have equal areas in tension and compression. (3) The radial stress is zero at the surface and equal to the tangential stress at the axis of the slug. The above criteria must be satisfied and they are useful to determine the accuracy of the calculations and the plots of stresses versus slug radius and area. However, the authors will show that these criteria are satisfied regardless of the accuracy of measured strains. The failure of each criterion to evaluate the accuracy of measured strains will be discussed individually. The terms used in the discussions are redefined below.

$$
\begin{aligned}
{ }_{\mathrm{L}}, \sigma_{\mathrm{T}}, \sigma_{\mathrm{R}}= & \begin{array}{l}
\text { longitudinal, tangential, and radial residual } \\
\text { stresses at the radius corresponding to the } \\
\text { bored-out area, } \mathrm{A}
\end{array} \\
\epsilon_{\mathrm{L}}, \epsilon_{\mathrm{T}}= & \begin{array}{l}
\text { measured longitudinal and tangential strains at } \\
\text { the radius corresponding to the bored-out area, } \\
\end{array} \\
\mu & \text { Poisson's ratio } \\
\Lambda=\epsilon_{\mathrm{I}}+\mu \epsilon_{\mathrm{T}}= & \text { strain parameter } \\
\theta=\epsilon_{\mathrm{T}}+\mu \epsilon_{\mathrm{I}}= & \text { strain parameter } \\
\mathrm{E}= & \text { Young's modulus } \\
\mathrm{A}_{\mathrm{O}}= & \text { original cross-sectional area of slug } \\
\mathrm{A}= & \text { bored-out cross-sectional area }
\end{aligned}
$$

The plot of longitudinal stress versus cross-sectional area must have equal areas in tension and compression.

For the criterion to be satisfied, the condition

$$
\int_{0}^{A_{O}}{ }^{\sigma} L d A=0
$$

must exist.

The Sachs equation for longitudinal stress is

$$
\sigma_{L}=\frac{E}{1-\mu^{2}}\left[\left(A_{0}-A\right) \frac{d \Lambda}{d A}-\Lambda\right]
$$


Multiply through this equation by $d A$ and replace the constant term with C

$$
{ }^{\sigma} \mathrm{d} A=C\left[A_{0} d \Lambda-A d \Lambda-\Lambda d A\right]
$$

Substitute

$$
A d \Lambda+\Lambda d A=d(\Lambda A)
$$

into Equation 7, leaving

$$
\sigma_{L} d A=C\left[A_{0} d \Lambda-d(\Lambda A)\right]
$$

The integral of this expression is

$$
\begin{aligned}
\int_{0}^{A_{0}} \sigma_{L} d A & =C^{\prime}\left[A_{0}(\Lambda)_{0}^{A_{0}}-(\Lambda A)_{0}^{A_{0}}\right] \\
& =C^{\prime}\left[A_{0} \Lambda_{0}-A_{0} \Lambda_{(0)}-A_{0} \Lambda_{0}+A(0) \Lambda_{(0)}\right]
\end{aligned}
$$

In an experimentally determined plot of $\Lambda$ versus $A, \Lambda=0$ where $A=0$ since no strain is measured prior to the first boring operation. Substitution of $\Lambda_{(0)}=0$ and $A_{(0)}=0$ into Equation 10 leaves

$$
\begin{aligned}
\int_{0}^{A_{0}} \sigma_{L} d A & =C^{\prime}\left[A_{0} \Lambda_{0}-A_{0} \Lambda_{0}\right] \\
& =0
\end{aligned}
$$

This shows that Equation 6 will be satisfied for any plot of $\Lambda$ versus A which has its origin at $0-0$. The accuracy of the measured strains cannot be verified by this criterion.

The plot of tangential stress versus radius must have equal areas in tension and compression.

This criterion is expressed by Equation 12 .

$$
\int_{0}^{r} \sigma_{T} d r=0
$$

The Sachs equation for tangential stress is

$$
\sigma_{T}=\frac{E}{1-\mu}\left[\left(A_{O}-A\right) \frac{d \theta}{d A}-\left(\frac{A_{O}+A}{2 A}\right) \theta\right]
$$

Multiply through this equation by $d A$ and replace the constant term with $\mathrm{C}$

$$
\sigma_{T} d A=C\left[A_{0} d \theta-A d \theta-\left(\frac{A_{O}+A}{2 A}\right) \theta d A\right]
$$


Substitute the relationships

$$
A=\pi r^{2} \quad d A=2 \pi r d r \quad A_{0}=\pi r_{0}^{2}
$$

in Equation 13

$$
\sigma_{\mathrm{T}} \mathrm{dr}=\mathrm{C}^{\prime}\left[\frac{\mathrm{r}_{\mathrm{O}}^{2}}{r} \mathrm{~d} \theta-r \mathrm{~d} \theta-\frac{\mathrm{r}_{0}^{2}}{\mathrm{r}^{2}} \theta \mathrm{d} r-\theta \mathrm{d} r\right]
$$

Substitute

$$
r d \theta+\theta d r=a(r \theta)
$$

and

$$
\frac{d \theta}{r}-\frac{\theta d r}{r^{2}}=d\left(\frac{\theta}{r}\right)
$$

into Equation 15

$$
\sigma_{T} d r=C^{\prime}\left[r_{0}^{2} d\left(\frac{\theta}{r}\right)-d(r \theta)\right]
$$

The integral of this expression is

$$
\begin{aligned}
\int_{0}^{r_{0}} \sigma_{\mathrm{T}} d r & =C^{\prime \prime}\left[r_{0}^{2}\left(\frac{\theta}{r}\right)_{0}^{r_{0}}-(r \theta)_{0}^{r_{0}}\right] \\
& =C^{\prime \prime}\left[r_{0}^{2}\left(\frac{\theta_{0}}{r_{0}}\right)-r_{0}^{2}\left(\frac{\theta}{r}\right)_{(0)}-r_{0} \theta_{0}+r_{(0)} \theta_{(0)}\right] \\
& =C^{\prime \prime}\left[r_{(0)} \theta_{(0)}-r_{0}^{2}\left(\frac{\theta}{r}\right)_{(0)}\right]
\end{aligned}
$$

As the value of $r$ approaches zero, the value of $\left(\frac{\theta}{r}\right)$ approaches $\left(\frac{d \theta}{d r}\right)$ (0) which is also zero. Since $r(0)$ and $\theta(0)$ are equal to zero, Equation 19 reduces to

$$
\int_{0}^{r} \sigma_{\mathrm{T}} \mathrm{dr}=0
$$

Thus, Equation 12 will be satisfied for any plot of $\theta$ versus A which has its origin at $0-0$ and in which $\left(\frac{d \theta}{d r}\right)_{(0)}$ is equal to zero. This latter condition is necessary if the stress is continuous across the axis of the slug. The accuracy of the measured strains cannot be verified by this criterion. 
The radial stress is zero at the surface and equal to the tangential stress at the axis of the slug.

The Sachs equation for radial stress is

$$
\sigma_{R}=\frac{E}{I-\mu^{2}}\left[\left(\frac{A_{0}-A}{2 A}\right) \theta\right]
$$

A simple substitution of $A=A_{0}$ shows that the radial stress is zero at the slug surface regardless of the value of the strain parameter, $\theta$. As the value of $A$ approaches 0 the limit of $\theta$ approaches $\left(\frac{d \theta}{d A}\right)_{(0)}$ and the limit of radial stress is

$$
\underset{A \rightarrow 0}{\sigma_{R}}=\frac{C}{2} A_{0}\left(\frac{d \theta}{d A}\right)_{(0)}
$$

from Equation 5. Similarly, the limit of tangential stress is

$$
\begin{aligned}
\underset{A \rightarrow 0}{\sigma_{T}}=C\left[A_{0}\left(\frac{d \theta}{d A}\right)_{(0)}-\frac{A_{O}}{2}\left(\frac{d \theta}{d A}\right)_{(0)}\right] \\
=\quad=\frac{C}{2} A_{0}\left(\frac{d \theta}{d A}\right)_{(0)}
\end{aligned}
$$

Thus, radial stress approaches tangential stress at the axis of the slug regardless of the values of the measured strains. The accuracy of the measured strains cannot be verified by this criterion. 